\title{
JNPH
}

Volume 6 No. 2 (Oktober 2018)

(C) The Author(s) 2018

\section{FAKTOR-FAKTOR YANG BERHUBUNGAN DENGAN KELENGKAPAN IMUNISASI DI WILAYAH KERJA PUSKESMAS TAIS TAHUN 2018}

\section{FACTORS RELATING TO IMMUNIZATION COMPLETENESS IN THE WORKING AREA OF THE PUSKESMAS TAIS IN 2018}

\section{WITI HERLAYATI}

\begin{abstract}
ABSTRAK
Latar belakang dan tujuan: Berdasarkan data dari Kementerian Kesehatan (2016) menunjukkan bahwa cakupan imunisasi dasar untuk bayi adalah 4,337,411 91,1 (91,1\%) sedangkan untuk Provinsi Bengkulu ada 30.243 (82,9\%). Hubungan antara pengetahuan, pendidikan dan sikap ibu dengan imunisasi dasar lengkap untuk bayi di Wilayah Kerja Puskesmas Tais Tahun 2018. Metode penelitian: yang digunakan dalam penelitian ini adalah penelitian analitik dengan menggunakan desain cross sectional. Populasinya adalah seluruh bayi di Wilayah Kerja Puskesmas Tais Bengkulu sebanyak 243 bayi. Pengambilan sampel dalam penelitian ini menggunakan metode sampling kebetulan dan ukuran sampel menggunakan rumus dan sebanyak 71 bayi. Metode pengumpulan data yang digunakan dalam penelitian ini menggunakan data primer, dianalisis secara univariat dan bivariat dengan menggunakan uji chisquare. Hasil penelitian menunjukkan bahwa mayoritas $(53,5 \%)$ responden dengan pendidikan menengah, sebagian besar $(87,3 \%)$ responden dengan pengetahuan baik tentang imunisasi, hampir separuh $(60,6 \%)$ responden dengan sikap tidak beralasan terhadap kelengkapan imunisasi dasar pada bayi. Ada hubungan yang bermakna antara pendidikan, pengetahuan dan sikap ibu dengan kelengkapan imunisasi dasar pada bayi di wilayah kerja Puskesmas Tais Tahun 2018. Kesimpulan dan Saran: untuk Puskesmas diharapkan dapat meningkatkan kualitas layanan konseling dan frekuensi konseling tentang risiko balita yang tidak diimunisasi sepenuhnya terhadap ibu yang memiliki bayi sehingga dapat meningkatkan pengetahuan ibu yang dapat berdampak pada peningkatan imunisasi bayi.
\end{abstract}

\section{Kata Kunci : Pendidikan, Pengetahuan, Sikap, Kelengkapan Imunisasi}

\begin{abstract}
Background and purpose: Based on data from the Ministry of Health (2016) showed that basic immunization coverage for infants was 4,337,411 91.1 (91.1\%) while for Bengkulu Province there were 30,243 (82.9\%). relationship between knowledge, education and mother's attitude with complete basic immunization for babies in the 2018 Tais Health Center area. Research method: used in this study is analytic research using cross sectional design. The population is all infants in the Tais Bengkulu Bengkulu Health Center Working Area as many as 243 babies. Sampling in this study uses the accidental sampling method and the sample size uses the formula so that 71 babies. Data collection methods used in this study were using primary data, analyzed univariately and bivariately by using the chi-square test. The results showed that the majority $(53.5 \%)$ of respondents with secondary education, most $(87.3 \%)$ respondents with
\end{abstract}


good knowledge about immunization, almost half (60.6\%) of respondents with an unvaporable attitude towards completeness of basic immunization in infants. There is a meaningful relationship between education, knowledge and attitudes of mothers with the completeness of basic immunization in infants in the working area of the 2018 Tais Health Center Conclusions and Suggestions: for the Puskesmas it is expected that it is expected to improve the quality of counseling services and the frequency of counseling about the risks of toddlers who are not fully immunized against mothers who have babies so as to increase maternal knowledge that can impact on increasing infant immunization

\section{Keywords : Education, Knowledge, Attitudes, Immunization Completeness}

\section{PENDAHULUAN}

Salah satu Indikator dalam mengukur keberhasilan pembangunan kesehatan adalah melalui Angka Kematian Ibu (AKI) dan Angka Kematian Bayi (AKB). Sampai saat ini AKB tahun 2016 di Indonesia masih tinggi yaitu 25.5 / 100.000 kelahiran hidup (Biro Pusat Statistik, 2016). Imunisasi berhasil menekan angka kematian ibu dan anak yang diakibatkan oleh tetanus, cacar, polio dan campak (Anonim, 2013). Berdasarkan data Ditjen P2P (2016), menunjukkan bahwa dibandingkan periode 2008-2011 cakupan imunisasi dasar lengkap periode tahun 20122015 di Indonesia mengalami penurunan. Cakupan imunisasi dasar lengkap berdasarkan data rutin pada tahun 2010-2013 mencapai target rencana strategi (Renstra) Kementerian Kesehatan. Namun pada tahun 2014 dan 2015 cakupan imunisasi tidak mencapai target renstra yang diharapkan.

Berdasarkan data Kementerian Kesehatan (2016) menunjukkan bahwa cakupan imunisasi dasar pada bayi sebanyak 4.337.411 91,1 (91,1\%) sedangkan untuk Propinsi Bengkulu sebanyak 30.243 (82,9\%) antara lain untuk cakupan imunisasi BCG (90,0\%), HB $<7$ hari $(80,8 \%)$, DPT- HB- HB (1) $(93,2 \%)$, DPT- HB- HB (3) $(90,5 \%)$, Polio (83,7\%), Campak (87,6\%). Berdasarkan data di atas Propinsi Bengkulu belum mencapai target cakupan imunisasi dasar lengkap yang telah ditetapkan pemerintah. Pemerintah menargetkan cakupan imunisasi dasar lengkap sebesar $91,5 \%$.

Imunisasi merupakan salah satu upaya yang dilakukan sebagai bentuk pencegahan penyakit. Semua anak dimulai sejak usia bayi, berhak mendapat imunisasi (Kinanti, 2013). Imunisasi adalah prosedur untuk meningkatkan derajat imunitas, memberikan imunitas protektif dengan menginduksi respons memori terhadap patogen tertentu atau toksin dengan menggunakan preparat antigen nonvirulen atau nontoksin (Baratawidjaya, 2006). Notoadmodjo (2005), mengemukakan bahwa perilaku dipengaruhi oleh factor-faktor predisposisi (predisposing factors) yaitu : pengetahuan, sikap, kepercayaan tradisi, sistem, nilai ; faktorfaktor pemungkin atau faktor-faktor yang mendukung (enabling factor) yaitu : fasilitas, sarana atau prasarana dan faktor-faktor yang memperkuat atau mendorong (reinforcing factors) yaitu : tokoh masyarakat (toma), peraturan, undang-undang, surat-surat keputusan dari pemerintah daerah atau pusat.

Data Puskesmas Tais didapatkan dalam tiga tahun terakhir yaitu tahun 2015 terdapat 185 bayi, yang lengkap imunisasi sebanyak 100 dan 85 tidak lengkap, tahun 2016 dari 217 bayi yang imunisasi lengkap sebanyak 177 bayi dan tidak lengkap sebanyak 40 bayi, tahun 2017 dari 243 bayi yang memiliki imunisasi lengkap sebanyak 213 dan yang tidak lengkap sebanyak 30 bayi. Survey awal yang peneliti lakukan di Puskesmas Tais pada tanggal bulan Maret tahun 2018, wawancara terhadap 9 orang Ibu yang mempunyai bayi usia 0-12 bulan diperoleh data bahwa 3 orang ibu memiliki pengetahuan yang baik tentang imunisasi dasar pada bayi memberikan Imunisasi dasar lengkap pada bayinya, 2 orang ibu memiliki pengetahuan yang baik tentang Imunisasi 
dasar pada bayi memberikan imunisasi dasar tidak lengkap pada bayi nya, 2 orang ibu memiliki pengetahuan yang kurang tentang imunisasi dasar pada bayi memberikan imunisasi dasar lengkap pada bayi nya, dan 2 orang ibu memilki pengetahuan yang kurang tentang imunisasi dasar pada bayi memberikan imunisasi dasar tidak lengkap pada bayi nya, dengan alasan ibu kurang informasi tentang manfaat imunisasi jadwal imunisasi dan tujuan dari imunisasi (Notoatmodjo, 2005)

Dari uraian dan data-data di atas, maka peneliti tertarik untuk meneliti tentang "faktor-faktor yang berhubungan dengan kelengkapan imunisasi dasar pada bayi di wilayah Puskesmas Tais Tahun 2018. Tujuan penelitian ini adalah untuk mengetahuinya hubungan pengetahuan, pendidikan dan sikap ibu dengan kelengkapan imunisasi dasar pada bayi di wilayah Puskesmas Tais Tahun 2018.

\section{METODE PENELITIAN}

Jenis penelitian yang digunakan adalah Deskriptif analitik dengan menggunakan desain Cross Sectional.

\section{HASIL PENELITIAN}

\section{Analisis univariat} tabel 1

Analisis univariat dapat dilihat pada

Tabel 1. Distribusi Responden Berdasarkan Pendidikan, Pengetahuan, Sikap Ibu dan Kelengkapan Imunisasi Bayi di Wilayah Kerja Puskesmas Tais Tahun 2018

\begin{tabular}{ccc}
\hline Variabel & Frekuensi & Persentase \\
\hline Pendidikan & & \\
Dasar & 10 & 14,1 \\
Menengah & 38 & 53,5 \\
Tinggi & 23 & 32,4 \\
\hline Pengetahuan & & \\
Kurang & 9 & 12,7 \\
Baik & 62 & 87,3 \\
\hline Sikap & & \\
Unvaporable & 43 & 60,6 \\
Vaporable & 28 & 39,4 \\
\hline Kelengkapan & & \\
Imunisasi & 47 & 66,19 \\
Tidak Lengkap & 24 & 33,90 \\
Lengkap & & \\
\hline Jumlah & 71 & 100 \\
\hline
\end{tabular}

Tabel 1. Menunjukkan bahwa sebagian kecil $(14,1 \%)$ responden dengan pendidikan dasar, sebagian besar $(53,5 \%)$ responden dengan pendidikan menengah dan hampir sebagian $(32,4 \%)$ responden dengan pendidikan tinggi. Sebagian kecil (12,7\%) responden dengan pengetahuan kurang dan sebagian besar $(87,3 \%)$ responden dengan pengetahuan baik tentang imunisasi. Sebagian $(60,6 \%)$ responden dengan sikap unvaporable terhadap kelengkapan imunisasi dasar pada bayi dan sebagian kecil $(39,4 \%)$ responden dengan sikap vaporable terhadap kelengkapan imunisasi dasar pada bayi. Sebagian $(66,20 \%)$ responden tidak lengkap dalam imunisasi dasar pada bayi dan sebagian kecil $(33,90 \%)$ responden lengkap dalam imunisasi dasar pada bayi

\section{Analisis Bivariat}

Analisis bivariat dapat dilihat pada tabel di bawah ini :

Tabel 2. Hubungan Pendidikan Ibu dengan Kelengkapan Imunisasi Dasar Pada Bayi di Wilayah Kerja Puskesmas Puskesmas Tais Tahun 2018 


\begin{tabular}{cccccccc}
\hline Variabel & \multicolumn{3}{c}{$\begin{array}{c}\text { Kelengkapan } \\
\text { Imunisasi }\end{array}$} & & Total & $\begin{array}{c}\boldsymbol{p} \\
\text { value }\end{array}$ \\
\cline { 2 - 5 } & $\begin{array}{c}\text { Tidak } \\
\text { lengkap }\end{array}$ & & & & & \\
\cline { 2 - 6 } & $\mathbf{f}$ & $\mathbf{\%}$ & $\mathbf{F}$ & $\mathbf{\%}$ & $\mathbf{f}$ & $\mathbf{\%}$ & 0,000 \\
\hline Pendidikan & & & & & & & \\
\hline Dasar & 7 & 70,0 & 3 & 30,0 & 10 & 100 & \\
\hline Menengah & 13 & 34,2 & 25 & 65,8 & 38 & 100 & \\
\hline Tinggi & 4 & 17,4 & 19 & 82,6 & 23 & 100 & \\
\hline Pengetahuan & & & & & & \\
\hline Kurang & 8 & 88,9 & 1 & 11,1 & 9 & 100 & 0,001 \\
\hline Baik & 16 & 25,8 & 46 & 74,2 & 62 & 100 & \\
\hline Sikap & & & & & & & \\
\hline Unvaforable & 19 & 44,2 & 24 & 55,8 & 43 & 100 & 0,042 \\
\hline Vaporable & 5 & 17,9 & 23 & 82,1 & 28 & 100 & \\
\hline
\end{tabular}

Dari tabel 2. diatas menunjukkan bahwa dari 10 kasus terdapat sebagian besar $(70,0 \%)$ responden dengan pendidikan dasar tidak lengkap imunisasinya. Hasil analisis uji chi square menunjukkan bahwa nilai $\mathrm{p}=$ 0,013 yang lebih kecil dari $\alpha$, berarti terdapat hubungan yang bermakna antara pendidikan ibu dengan kelengkapan Imunisasi dasar pada bayi di wilayah kerja Puskesmas Tais Tahun 2018. Dari 9 kasus terdapat hampir seluruh $(88,9 \%)$ responden dengan pengetahuan kurang memiliki imunisasi tidak lengkap. Hasil analisis uji fisher excat test menunjukkan bahwa nilai $\mathrm{p}=0,000$ yang lebih kecil dari $\alpha$, berarti terdapat hubungan yang bermakna antara pengetahuan ibu dengan kelengkapan Imunisasi dasar pada bayi di wilayah kerja Puskesmas Tais Tahun 2018. Dari 43 kasus terdapat sebagian $(44,2 \%)$ responden dengan sikap unvaporable tidak lengkap imunisasinya. Hasil analisis uji chi square menunjukkan bahwa nilai $\mathrm{p}=$ 0,042 yang lebih kecil dari $\alpha$, berarti terdapat hubungan yang bermakna antara sikap ibu dengan kelengkapan Imunisasi dasar pada bayi di wilayah kerja Puskesmas Tais Tahun 2018.

\section{PEMBAHASAN}

Hasil penelitian menunjukkan bahwa terdapat hubungan yang bermakna antara pengetahuan $\mathrm{ibu}$ dengan kelengkapan
Imunisasi dasar pada bayi di wilayah kerja Puskesmas Tais Tahun $2018(\mathrm{p}=0,001)$.

Hasil ini menunjukkan bahwa pengetahuan merupakan salah satu faktor yang memegang peranan penting terhadap kelengkapan imunisasi bayinya. pengetahuan ibu dapat diperoleh dari pendidikan atau pengamatan serta informasi yang didapat seseorang. Pengetahuan dapat menambah ilmu dari seseorang serta merupakan proses dasar dari kehidupan manusia. Melalui pengetahuan, manusia dapat melakukan perubahan-perubahan kualitatif individu sehingga tingkah lakunya berkembang.

Pengetahuan berpengaruh terhadap sikap seseorang sesuai dengan pemikirannya, kalau positif akan menimbulkan sikap positif demikian juga sebaliknya. Pengetahuan ibu yang kurang akibat ibu tidak mendapatkan penjelasan yang baik atau kurangnya informasi (penyuluhan) tentang pentingnya imunisasi sehingga banyak para ibu yang salah persepsi apabila diimunisasi akan mengakibatkan demam, luka parut, bengkak sehingga ibu tidak berniat untuk mengimunisasikan bayinya. Hal ini bertolak belakang pada ibu yang berpengetahuan baik mengimunisasikan bayinya dengan imunisasi yang lengkap.

Ibu yang memiliki pengetahuan rendah dan jauh dari informasi akan mengalami kesulitan dalam menerima imunisasi hal ini disebabkan karena ketidaktahuan ibu mengenai pengertian, tujuan, manfaat, waktu pemberian, frekuensi pemberian, jarak pemberian, bentuk vaksin, cara pemberian, tempat pemberian, dampak bila tidak diberikan, tempat pelayanan dan efek samping tentang imunisasi.

Pengetahuan adalah hasil tahu dan ini terjadi setelah orang melakukan penginderaan terhadap objek tertentu melalui mata dan telinga. Pengetahuan merupakan domain yang sangat penting untuk terbentuknya tindakan seseorang (Notoatmodjo, 2007).

Hal ini sejalan dengan Menurut Slamet (1999), pengetahuan yang mencakup dalam domain kognitif mempunyai 6 (enam) tingkat yaitu tahu diartikan sebagai mengingat 
suatu materi yang telah dipelajari sebelumnya, memahami diartikan sebagai suatu kemampuan menjelaskan secara benar tentang objek yang diketahui dan dapat menginterpretasikan materi tersebut secara benar. Aplikasi diartikan sebagai kemampuan untuk menggunakan materi yang telah dipelajari atau kondisi yang sebenarnya, analisa merupakan suatu kemampuan untuk menjabarkan materi atau suatu objek ke dalam komponen-komponen, tetapi masih dalam suatu kemampuan untuk menyusun formulasi baru dari formulasi-formulasi yang ada. Evaluasi ini terkait dengan kemampuan untuk melakukan justifikasi atau penilaian terhadap suatu materi atau objek.

Depkes RI (2005) menyatakan bahwa tanggung jawab keluarga terutama para ibu terhadap imunisasi bayi/ balita sangat memegang peranan penting sehingga akan diperoleh suatu manfaat terhadap keberhasilan imunisasi serta peningkatan kesehatan anak. Pemanfaatan pelayanan kesehatan dipengaruhi oleh komponenkomponen pendorong yang menggambarkan faktor-faktor individu secara tidak langsung berhubungan dengan penggunaan pelayanan kesehatan yang mencakup beberapa faktor, terutama faktor pengetahuan ibu tentang kelengkapan status imunisasi dasar bayi atau anak. Komponen pendukung antara lain kemampuan individu menggunakan pelayanan kesehatan yang diperkirakan berdasarkan pada faktor pendidikan, pengetahuan, sumber pendapatan atau penghasilan.

Hasil ini sejalan dengan penelitian Endah (2008), menunjukkan bahwa pengetahuan ibu mempunyai pengaruh positip terhadap kelengkapan imunisasi dasar, yang berarti bahwa semakin baik pengetahuan ibu Faktor-faktor Yang Mempengaruhi Kelengkapan Imunisasi Dasar dengan nilai koefisien (B) $=0,209$. Hasil penelitian menunjukkan bahwa terdapat hubungan yang bermakna antara sikap ibu dengan kelengkapan Imunisasi dasar pada bayi di wilayah kerja Puskesmas Puskesmas Tais Kabupaten Seluma Tahun $2018(\mathrm{p}=0,042)$.
Sikap sebagai salah satu faktor predisposisi seseorang untuk berperilaku. Faktor sikap mendorong atau memotivasi seseorang untuk berperilaku dalam memperoleh pelayanan kesehatan atau dengan kata lain semakin positif sikap seseorang maka akan semakin baik perilaku yang dimilikinya.

Walaupun demikian sikap tidaklah berdiri sendiri sebagai faktor yang berhubungan dengan pemberian imunisasi pada ibu bayi. Pendidikan dan pengetahuan akan mempengaruhi pembentukan sikap ibu. Sikap ibu tentang imunisasi ini meliputi tanggapan persepsi tentang manfaat imunisasi. Sikap merupakan kesiapan untuk bertindak.

Ibu dengan pendidikan yang rendah dan pengetahuan yang kurang maka dengan sendirinya akan membentuk sikap yang tidak mendukung atau unfavorable terhadap pelayanan imunisasi. Namun ibu meski berpendidikan rendah tapi memiliki pengetahuan yang baik mengenai imunisasi dengan sendirinya akan membentuk sikap yang mendukung atau favorable dan berupaya untuk mendapatkan imunisasi selengkapnya.

Hasil penelitian ini sejalan dengan teori yang mengatakan bahwa sikap merupakan reaksi atau respon seseorang yang masih tertutup terhadap suatu stimulasi atau obyek. Manifestasi sikap itu tidak dapat langsung dilihat, tetapi hanya dapat ditafsirkan terlebih dahulu dari perilaku yang tertutup. Sikap itu merupakan kesiapan atau kesediaan untuk bertindak dan bukan merupakan pelaksana motif tertentu (Notoatmodjo, 2007).

Menurut Triana (2015), menyebutkan bahwa sikap masyarakat yang cukup tentang imunisasi perlu diperbaiki agar generasi penerusnya dapat terhindar dari penyakit menular tertentu. Hal yang perlu diperbaiki adalah meningkatkan penyuluhan kepada masyarakat akan pentingnya imunisasi, efek samping dari imunisasi serta kandungan dari vaksin imunisasi. Hal ini dilakukan dengan harapan tidak ada lagi anggapan bahwa imunisasi tidak penting. Hasil penelitian 
Alfiyan (2018), menunjukkan bahwa terdapat hubungan karakteristik, pengetahuan, sikap, dan tindakan ibu dengan kepatuhan imunisasi di Wonokusumo, Surabaya

\section{KESIMPULAN}

Dari hasil penelitian, maka dapat ditarik kesimpulan sebagai berikut :

1. Sebagian besar $(53,5 \%)$ responden memiliki pendidikan menengah.

2. Sebagian besar $(87,3 \%)$ responden memiliki pengetahuan baik imunisasi.

3. Hampir sebagian $(60,6 \%)$ responden dengan sikap unvaporable terhadap kelengkapan imunisasi dasar pada bayi.

4. Sebagian $(66,20 \%)$ responden tidak lengkap dalam imunisasi dasar pada bayi

5. Ada hubungan yang bermakna antara pendidikan ibu dengan kelengkapan Imunisasi dasar pada bayi di wilayah kerja Puskesmas Tais Tahun 2018

6. Ada hubungan yang bermakna antara pengetahuan ibu dengan kelengkapan Imunisasi dasar pada bayi di wilayah kerja Puskesmas Tais Tahun 2018

7. Ada hubungan yang bermakna antara sikap ibu dengan kelengkapan Imunisasi dasar pada bayi di wilayah kerja Puskesmas Tais Tahun 2018

\section{SARAN}

Kepada peneliti selanjutnya
diharapkan agar berupaya lebih
mengembangkan dan memperdalam bahasan
tentang faktor-faktor yang berhubungan
dengan kelengkapan imunisasi dengan
menggunakan desain penelitian yang berbeda.

\section{DAFTAR PUSTAKA}

Ajeng, K, 2013, Perawatan Bayi Baru Lahir Imunisasi Ini Wajib diBerikan pada Bayi Anda, diakses pada tanggal 05 Mei 2013, pada www.detik.com

Anonim, 2013, Imunisasi Tekan Angka

Kematian Anak, diakses pada tanggal 18
April 2013, pada www.beritasatu.com

Arikunto, 2010, Prosedur Penelitian Suatu

Pendekatan Praktek Cetakan Keduabelas,

PT. Rineka Cipta , Jakarta

Baratawidjaja, 2009, Imunologi Dasar, Balai

Penerbit Fakultas Kedokteran Indonesia, Jakarta

Dinkes Kabupaten Seluma, 2017, Profil Kesehatan Kabupaten Seluma Tahun 2017, Dinkes Seluma

Muchlastriningsih, Enny, 2005, PenyakitPenyakit Menular Yang Dapat Di Cegah Dengan Imunisasi ( Pd3i) Di Indonesia. Majalah: Cermin Dunia kedokteran

Notoatmodjo, 2005, Promosi Kesehatan, Teori Dan Aplikasi .Betapa Cetakan Pertama Rineka Cipta ,Jakarta. , 2007, Promosi Kesehatan dan Ilmu

Perilaku, Rineka Cipta, Jakarta. ,2010, Metodologi Penelitian Kesehatan,

Rineka Cipta, Jakarta , 2014, Ilmu Perilaku Kesehatan. Rineka Cipta, Jakarta.

Pusat Pendidikan dan Pelatihan Tenaga Kesehatan, 2014, Buku Ajar Imunisasi

Slameto, 2010, Belajar dan Faktor-faktor yang Mempengaruhinya, Rineka Cipta, Jakarta

Sugiyono, 2011, Metode Penelitian Kuantitatif Kualitatif, Alfabeta, Bandung 